\title{
El Arte es garantía de cordura: \\ Louise Bourgeois, memorias traumáticas y su poder resiliente ${ }^{1}$
}

\section{María Campo- Redondo ${ }^{2}$}

Louise Bourgeois (1911-2010) fue una mujer parisina de nacimiento y neoyorkina por adopción, de múltiples facetas, con una personalidad arrolladora, compleja, misteriosa, vulnerable, quizás difícil pero balanceada, y sobre todo y a pesar de todo: impecable y brutalmente honesta.

Esculpía, moldeaba, fusionaba materiales, pintaba, dibujaba, grababa, diseñaba interiores y exteriores también, cosía, tejía, reparaba textiles, hilaba, ingeniaba. Como artista y luchadora, se resistía a mimetizarse con cualquier movimiento, y mucho menos, que la academia y los colectivos políticos se apropiaran de su estilo en favor de una causa. Orgullosa, altiva al declarar, "Soy una mujer, y por lo tanto no necesito ser feminista" (Jiménez Arenas, 2006).

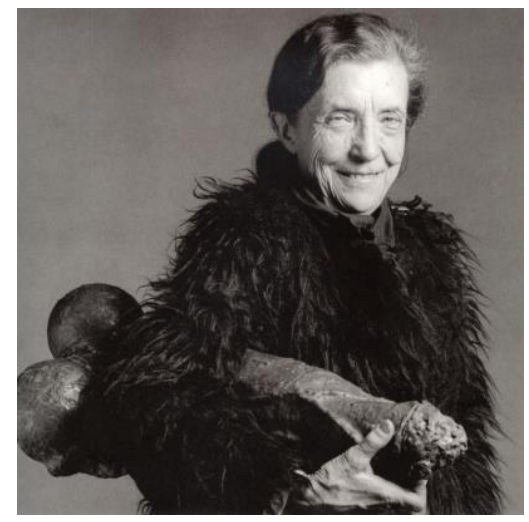

Sin embargo, cuenta Jerry Gorovoy, su asistente y amigo personal por más de treinta años, que una de las primeras obras que Loise Bourgeois logró vender en una exposición, antes de su reconocimiento mundial, titulada inicialmente "El ciego llevando al ciego", fue a parar a Australia. La compró un coleccionista, y la utilizaron en ese país como emblema para

\footnotetext{
${ }^{1}$ Extractos de esta monografía fueron previamente presentados en el ciclo de mujeres celebres, dedicado a Louis Bourgeois, organizado por la Fundación Anna O, Málaga, España, el 16 de marzo de 2015.

2 Campo-Redondo, María. (2017). El arte es garantía de cordura: Louise Bourgeois, memorias traumáticas y su poder resiliente. Clínica e Investigación Relacional, 11 (2): 460-467. [ISSN 1988-2939] [Recuperado de www.ceir.info] DOI: 10.21110/19882939.2017.110219
} 
despenalizar la prostitución (Xenakis, 2008). Así fue la obra de Louise Bourgeois: impredecible.

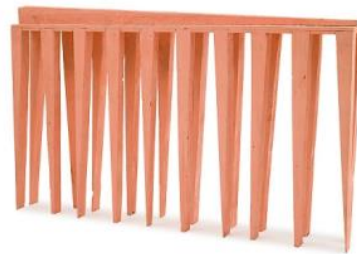

Pero no solo fue una artista plástica. También fue narradora, podríamos decir que intensa, por no llamarla compulsiva: escribía constantemente, en todas partes, dejándose llevar por la frase corta, enigmática e incisiva; también produjo poesía y música (grabó una canción que ella misma compuso y la cantó a los ochenta y cuatro años), fue protagonista de numerosas entrevistas y hasta personaje principal de documentales.

En España, su obra tiene una presencia cautivante. Bilbao, acogió una de sus gigantescas arañas como hija adoptiva de la ciudad, y junto al Guggenheim, testifican la revitalización del río Ebro, dándole a esa ciudad industrial, gris y fría, el impulso artístico y la vitalidad que la ha hecho una de las ciudades más importantes de destino cultural de Europa. Y Málaga, como ciudad de los museos, no podía quedarse atrás. El Centro de Arte Moderno (CAC) tiene algunas de sus obras en su colección permanente.

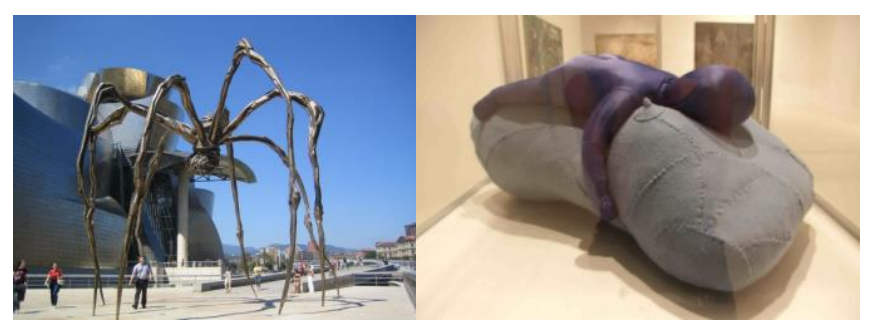

La plástica de Loise Bourgeois también ha sido utilizada como fuente de inspiración en el arte cinematográfico. Solo comentaré brevemente dos ejemplos.

En "La piel que habito" (2011), Almodovar, utiliza las obras de Louise Bourgeois para que su protagonista Vicente, pudiese soportar el encierro, hasta convertirse en mujer. $Y$ ya transformado en Vera, con un cuerpo cosido a lo "bourgeois", ésta tolera su metamorfosis haciendo yoga, con posiciones que recuerdan la famosa escultura de "el Arco de la Histeria". Al final de la película, en los créditos, el director Manchego le agradece a Loise Bourgeois su grandeza. 


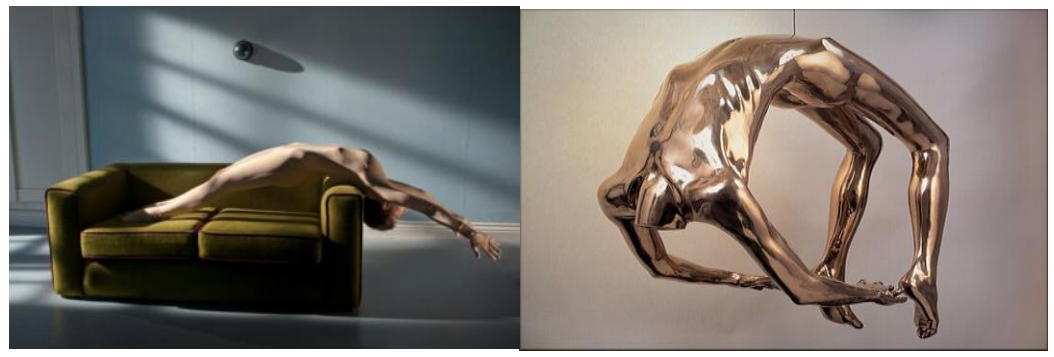

Otro director que usa sus gigantescas arañas es el canadiense Villanueve. En la película "Enemy" (2013), basada en una novela de José Saramago, la obra de Bourgeois está presente en las tomas de la inmensa Toronto, y el emblemático insecto es usado en el poster promocional, insertado en la cabeza del protagonista. Parece que todo lo que toca Louise Bourgeois se transforma.

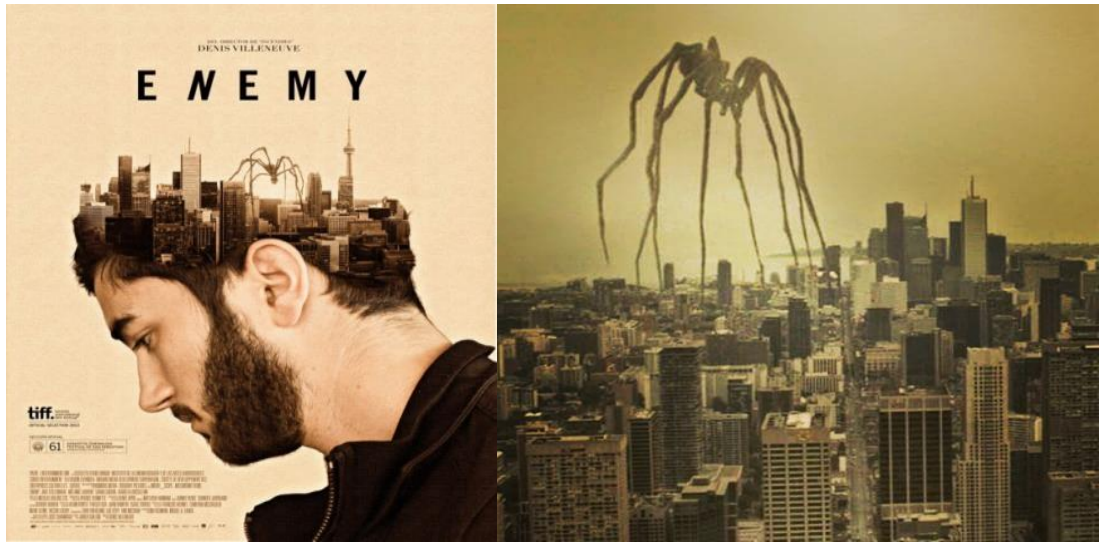

También fue una interlocutora con las generaciones mas jóvenes. Ya en su avanzada edad, en su casa de Chelsea, N.Y, organizaba sesiones dominicales, donde se encontraba con artistas jóvenes seguidores de su obra. No le agradaba tanto la idea de que ellos se interesaran por ella, sino ella en conocer la subjetividad de los asistentes. Cuentan los que tuvieron la oportunidad de participar en una de esas reuniones, que les recibía en un salón que disponía de sillas colocadas en un círculo (no aceptaba sus currículos, ni permitía entrevistas formales). Ella quería mantener la esencia real e íntima del encuentro. Se interesaba por sus procesos personales cuando creaban. Probablemente, a sabiendas de su poder inquisitorio, disponía de unas botellas de licor, para que aquellos que se intimidaran con su presencia, pudiesen tomar una copitas, "relajarse", y así hablar tranquilamente de sus miedos y vivencias relacionadas con sus creaciones.

A pesar de que se burlaba y criticaba duramente al psicoanálisis, fue abnegada y comprometida con su psicoterapia personal. Sus diarios y anotaciones privadas, encontradas en una caja en el trastero de su casa, documentan minuciosamente su recorrido con el Dr. Lowenfleld, su psicoanalista por muchos años. Padecía insomnio crónico, 
depresiones oscilantes, rabietas, y en ocasiones ataques de agarofobia que le impedían salir de su casa, así como una intolerancia a su propia agresión, que la hacía atacar cuando más vulnerable se encontraba: cuando tenía miedo. Tenía obsesiones: guardaba incontables objetos, poseía varias casas sin habitar. Su niñez, con sus traumas y recuerdos, cuenta ella misma en sus escritos y entrevistas, fueron siempre la fuente de su inspiración: "Mi infancia nunca ha perdido su magia, nunca ha perdido su misterio y nunca ha perdido su drama. Todos mis trabajos de los últimos 50 años tienen su origen en mi niñez" (Mayayo, 2003).

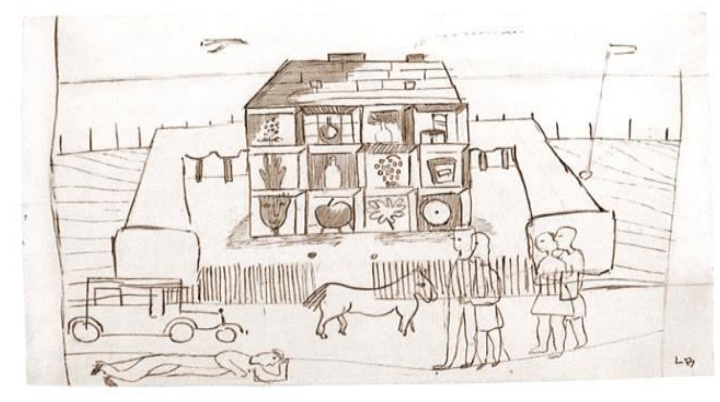

Algunos analistas la han catalogado como la primera artista psicoanalíticamente orientada de la contemporaneidad y el Museo Sigmund Freud en Londres organizó en el año 2012 una exposición en honor a ella.

Cómo abordar a esta mujer, con una producción extensísima, y de la que se ha escrito y publicado incontables obras. El psicoanálisis nos puede dar algunas pistas.

Sabemos que el descubrimiento freudiano de la existencia de mecanismos inconscientes que regulan el comportamiento humano constituyó una conocida revolución en la concepción del hombre, tanto en su vertiente creativa como también en la destructiva, y fue un aporte capital para el tratamiento de sus distintas condiciones patológicas.

Freud y los grandes desarrollos postfreudianos han explicado exhaustivamente cómo y por qué nos comportamos y nos enfermamos de una determinada manera y el papel de los vínculos y de la fantasía han sido relevante para explicar la patología. También son importantes las consideraciones sobre la "virtualidad sana" que existiría aún en los pacientes más graves, pues esto implicaría la existencia de potenciales inconscientes salutogénicos, coexistiendo con las tradicionales resistencias y escisiones inconscientes.

Freud nos ayudó a comprender cómo el pasado se entrelaza con lo inconsciente y cómo esto permea todo lo que hacemos a lo largo del recorrido por la vida. Sabemos que se interesó por los relatos de sus pacientes, muchos de ellos con intensos sufrimientos nerviosos. Poco a poco, a través de una escucha sistemática, paciente y tenaz, llegó a descubrir que el 
sufrimiento del que le hablaban tenía sus orígenes en el pasado, en la infancia desdichada de sus vidas, llegando a proponer la importancia de la sexualidad infantil. También planteó que la eficacia traumática de un evento no depende solo de su magnitud, sino más bien de su forma de ser vivenciado. Esto significa que tradicionalmente se asocie trauma con vulnerabilidad.

Qué conceptos entonces podríamos utilizar para entramarnos en la vida de Louise Bourgeois y definir algo de su personalidad. Coordenadas provenientes de la teoría psicoanalítica hay muchas, entre las más significativas se me ocurren "arte para entender el pasado", "el inconsciente y lo pulsional como fuerza creadora", "lo arquetípico", "los recuerdos encubridores", "lo traumático", "la sublimación", y "la resiliencia" entre otras. Escojo esta última para dar cuenta de la capacidad transformadora de esta mujer.

Qué entendemos por resiliencia. Siguiendo a Zukerfeld y Zukerfeld (2011), podríamos decir que es la capacidad humana de enfrentar, sobreponerse y ser transformado por experiencias de adversidad.

Que Louise Bouigeois tenga memorias dolorosas y humillantes de su niñez es un hecho, que se puede corroborar en sus declaraciones públicas y en sus anotaciones privadas, así como en la carga afectiva que le impregnaba a sus obras. Estudiándola, imaginamos, y casi sentimos, las amarguras y dolores que Bourgeois probablemente experimentó. Podemos apreciar también el potencial creador de su vida interior, y sobre todo, su fantasía para transformar sus demonios más íntimos, en una fuerza vital sorprendente. Ya desde niña, poseía una función reflexiva y una capacidad increíblemente excepcional para mentalizar los sentimientos, asociada a una empatía y un conocimiento relacional implícito que le permitía percibir sus propios estados mentales y los de aquellos que la rodeaban.

Y es aquí donde el concepto de resiliencia viene en nuestro auxilio.

Desde pequeña, nos advierte ella misma, tuvo siempre a su alcance una capacidad reparadora inimaginable. Cuenta la propia artista, que su padre tenía un humor negro muy humillante (dicen que ella también podía ser irónicamente burlona). 


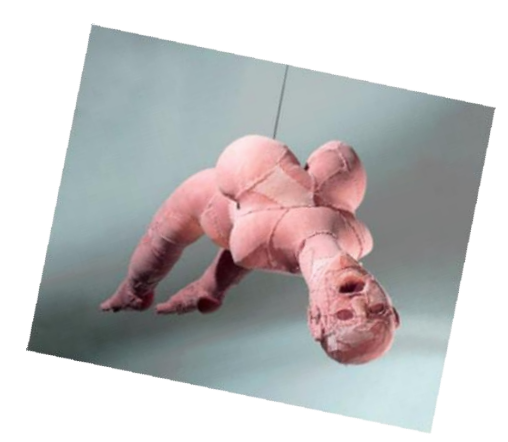

Afirman los que han seguido su biografía (Mayayo, 2003) que ella recuerda haber hecho su primera obra escultórica alrededor de los ocho años, y ya a esa edad se anotaba una capacidad resiliente pasmosa. En la sobremesa, su padre hacía chistes grotescos y muchos, dice ella, los dirigía a la pequeña Louise. Ella agarraba una masa de pan, la mezclaba con saliva, y poco a poco, sin que nadie lo supiese, moldeaba al padre, y luego lo cortaba en pedazos y se lo comía. Así comenzó esta niña a utilizar la escultura como un "delirio reparador". Su arte, íntimamente intrincado a su ser, a sus vivencias, nos permite conectarnos con sus partes escindidas, y a la vez nos muestra cómo tender puentes entre las grietas que se iban abriendo en su polaridad humana. Louise Bourgeois pudo asir su lado mas oscuro para transformarse y trascender, no solo a ella misma, sino a la época en que vivió.

A lo largo de su vida mostró un desarrollo resiliente frente a la adversidad familiar en la que creció, generando una metamorfosis subjetiva constante, producto de la activación de un potencial mentalizador que le sirvió para la creación de condiciones psíquicas nuevas, que transformaban el efecto traumático en contenidos psíquicos más tolerables, y en una obra artística digna de admiración. Dice Cyrulnik (2001), el psicoanalista francés que más ha estudiado la resiliencia, que para metamorfosear el horror y el trauma, hay que crear lugares donde se exprese la emoción. Creo que esto fue lo que hizo Louis Bougeois toda su vida.

También nos plantea Rodríguez (2009) que la resiliencia implica crear respuestas nuevas para situaciones que parecen no tener salida y este elemento de novedad da cuenta de la ligazón entre la resiliencia y el sentido del humor. Y vaya si lo tenía la Bourgeois! Pienso que el desarrollo resiliente de nuestra protagonista cuestiona los determinismos lineales; ella produjo en su psiquismo y en toda su centenaria vida una fuerte transformación de su subjetividad que logró convertir el daño en fortaleza. Su poder resiliente, brutalmente honesto, puede ser tomado como contraparte a la época que le toco vivir, donde la rabia por un maltrato sostenido puede llevar a una mujer a amputarle el pene a su marido, como el expresa. Este material es para uso científico y profesional exclusivamente y puede contener información clínica sensible. Los editores no se responsabilizan de los contenidos de los autores. Dirigir las consultas sobre derechos y autorizaciones a ceir@psicoterapiarelacional.es 
caso de Lorena Bobitt, o una infidelidad se vende en platos de televisión y se convierte al personaje en heroína y princesa del pueblo. Loiuse Bourgeois en cambio, usó sus memorias traumáticas para transformar su rabia y humillación en fuerza creadora. Ahí reside su poder resiliente. Creo que Louise Bourgeois hizo gala de una valentía confesional digna de admirar. Ya para terminar, y haciendo honor a ese legado que nos dejó, hago una confesión personal. No conocí personalmente a Louis Bourgeois, pero adentrándome en su obra, tengo la convicción de que si nos hubiésemos encontrado cara a cara, inmediatamente nos reconoceríamos como dos seres que se especularizan, no se si de modo virtual, simbólico, imaginario, real o de algún otro registro. He visto algunas de sus obras y reconozco que han penetrado en mi conciencia. A través del estudio de algunos aspectos de su vida, me he compenetrado más conmigo misma. Partes escindidas de mi están ahí, en su obra, yo las veo, sin ella saberlo. Ese podría ser mi mejor homenaje a esta extraordinaria mujer: su obra me ha servido para dialogar íntimamente con partes de mí misma. Ya lo intuía cuando afirmaba, "no me interesa dejar imágenes, me interesa comunicar sentimientos". Creo que a Loiuse Bourgeois, le hubiese producido satisfacción, que alguien, además de ella, con el acercamiento a su obra, se conectase más con la humanidad, pues nada de lo humano le fue ajeno. Y esto, Louise Bourgeois lo puso en práctica toda su vida. "El arte es una garantía de sanidad y esto no es ninguna broma". Así finalizaba ella una de sus tantas declaraciones. Y así termino yo la mía.

\section{REFERENCIAS:}

Almodovar. A y García E. (productores) y Almodovar, P. (director). (2011). La piel que habito [Cinta cinematográfica]. España: El Deseo

Bourgeois, L. (2002). Destrucción del padre - Reconstrucción del padre ${ }_{L}$ Editorial Editorial Síntesis. Madrid, España.

Cyrulnik, B. (2001). La maravilla del dolor: el sentido de la resiliencia. Ediciones Granica S.A. Barcelona, España

Feige, K. (productor) y Villeneuve D. (director). (2013). Enemy [Cinta cinematográfica]. US: Mecanismo Films

Jiménez Arenas, I. M. (2006). La expresión plástica de Louise Bourgeois. Estrategias feministas para una praxis terapéutica. UNIVERSITAT DE VALENCIA. Servei de Publicacion recuperado de www.mav.org.es/documentos/.../Tesis\%2oLouise\%2oBourgeois.pdf

Mayayo, P. (2003). Historias de mujeres, Historias del arte. Editorial Cátedra, Madrid, España

Rodríguez, D. (2009). Resiliencia y tendencia criminal: factores protectores de comportamiento antisocial. Revista Criminalidad, Volumen 51, Número 1, junio, pp. 131-145. Bogotá, D. C., Colombia ISSN $1794-3108$ 
Xenakis, M. (2008). Louise Bourgeois: The Blind Leading the Blind, Publisher Actes Sud, Paris, France

Zukerfeld, R. y Zukerfeld R. Z. (2011). Sobre el Desarrollo Resiliente: Perspectiva Psicoanalítica. Clínica Contemporánea (Colegio Oficial de Psicólogos de Madrid) Vol. 2, n. ${ }^{\circ}$ 2, - Págs. 105-120. http://dx.doi.org/10.5093/cc2011v2n2a1 